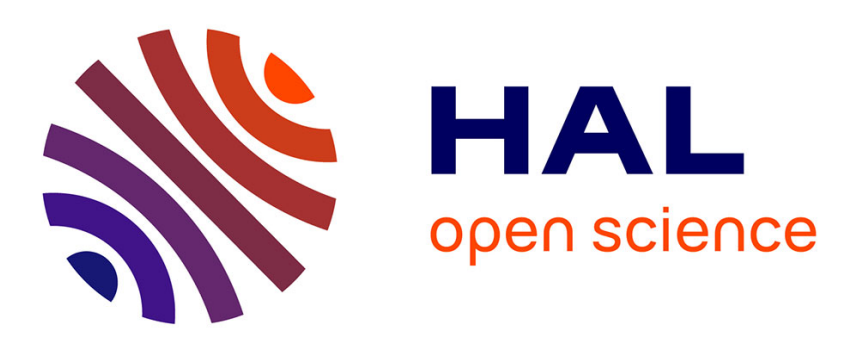

\title{
Optimal Scheduling of Storage Devices in Smart Buildings Including Battery Cycling
}

\author{
Carlos Adrian Correa Florez, Alexis Gerossier, Andrea Michiorri, Georges \\ Kariniotakis
}

\section{- To cite this version:}

Carlos Adrian Correa Florez, Alexis Gerossier, Andrea Michiorri, Georges Kariniotakis. Optimal Scheduling of Storage Devices in Smart Buildings Including Battery Cycling. 12th IEEE Power and Energy Society PowerTech Conference - PowerTech, Jun 2017, Manchester, United Kingdom. 10.1109/PTC.2017.7981199 . hal-01520365

\section{HAL Id: hal-01520365 \\ https://hal-mines-paristech.archives-ouvertes.fr/hal-01520365}

Submitted on 10 May 2017

HAL is a multi-disciplinary open access archive for the deposit and dissemination of scientific research documents, whether they are published or not. The documents may come from teaching and research institutions in France or abroad, or from public or private research centers.
L'archive ouverte pluridisciplinaire HAL, est destinée au dépôt et à la diffusion de documents scientifiques de niveau recherche, publiés ou non, émanant des établissements d'enseignement et de recherche français ou étrangers, des laboratoires publics ou privés. 


\title{
Optimal Scheduling of Storage Devices in Smart Buildings Including Battery Cycling
}

\author{
Carlos Adrian Correa, Alexis Gerossier, Andrea Michiorri, Georges Kariniotakis, Senior Member IEEE \\ MINES ParisTech, PSL-Research University, PERSEE -Processes, Renewable Energies and Energy Systems- \\ 06904 Sophia Antipolis, France \\ carlos-adrian.correa_florez@mines-paristech.fr
}

\begin{abstract}
This paper presents an optimization model for energy management in smart buildings, when electrochemical and thermal storage are considered as flexibilities to achieve minimum operation costs. The optimization problem takes into account the battery's cycling cost and the possibility of storing energy in the electric water heater. To deal with the cycling aging process, the problem is decomposed into two subproblems that are iteratively solved, in which a Particle Swarm Optimization decides the battery's State of Charge and then a day-ahead dispatch takes place to determine the total operation cost. This approach allows us to deal with the non-linearities of battery aging in a simple an effective way. The results show that the potential presence of both storage technologies has a positive impact on the operation costs; they also show the impact on the device settings when battery's cycling aging cost is considered. This methodology has been developed in the context of the Horizon 2020 project SENSIBLE as part of the tasks related to the use case, Flexibility and Demand Side Management in Market Participation.
\end{abstract}

Index Terms-Smart buildings, Storage, Optimization, battery cycling.

\section{INTRODUCTION}

In order to face the challenges raised by contemporary power systems, new approaches featuring descentralized generation and coordination with demand side flexibility have gained substantial attention in recent years. Some of these new schemes are being developed in the medium and low voltage grid, and most recently at building and home level, leading to the development of concepts such as Smart Residential Buildings (SRB) and Home Energy Management Systems (HEMS) [1].

These possibilities, in a smartgrid context, make it possible to exploit the flexibility capabilities provided by renewables, storage technologies, demand response (DR) and interaction with the grid [2]. In the concrete case of the present work, the aim is to analyze the interaction between thermal and electric storage in an SRB, considering battery aging.

In particular, the aging process of storage devices is complex, and depends on internal chemical reactions with electrode interfaces, and the degradation of active materials due to cycling and aging of non-active components [3]. This degradation process can be tracked and modeled by determining the

This work was carried out as part of the research and innovation project SENSIBLE (Storage ENabled SustaInable energy for BuiLdings and communitiEs - www.h2020-projectsensible.eu), which has received funding from the European Union under the Horizon 2020 Framework Programme gran agreement No 645963. cycling patterns, the respective Depth of Discharge (DOD) and the rate at which this process occurs [4].

To include this process in the operation of SRB, some research has been published in recent years. For example, the work presented in [5] evaluates the impacts of peak shaving when DR potential is enhanced through different storage technologies. To include cycling of storage devices, a set of values of the energy that can be cycled are predefined and analyzed.

Other models that consider predefined values or limits for the total energy that can be cycled, in the form of equivalent State of Charge (SOC) or DOD values, are presented in [6], [7]. The research in [8] includes detailed behaviour of battery voltages and currents due to operating DOD, with the aim of managing resources in residential microgeneration systems.

Regarding management models for joint thermal and electric storage technologies at the residential level, approaches include that presented in [9], which proposes a residential microgrid in which thermal and electric storage make it possible to shave the demand peak and enhance the system's self-sufficiency. The approach in [10] presents a methodology for intraday management of PV and Electric Water Heaters (EWH) in an LV network, with the EWH acting as a flexible load in order to achieve minimum operation costs.

Reference [11] presents an optimization problem for dayahead market that minimizes retailer costs represented by imports/exports and gas costs, along with expected balancing costs in real time operation. The model includes thermal load and also electro-thermal storage, which can generate or consume power.

Sizing and operation of storage devices in smart buildings is presented in [12], including electrical and thermal storage. This study concludes that thermal storage is crucial to reduce energy costs. However, it does not take into account cycling aging and points out that batteries might not be economical due to investment costs and short lifetime.

A recent paper [13] presents a cooperative scheme of SRB for optimal management of resources, considering batteries, thermal storage and electrical vehicles. Although cycling is not taken into account, this study constitutes an interesting benchmark given that different network configurations are presented, showing the importance of exploiting operational flexibilities when different interactions are analyzed.

Although the above literature review is not exhaustive, it represents the trends related to the topics in discussion and 
shows that the current literature leaves room for significant development regarding the integration of storage technologies in SRB including battery cycling.

For the present work, an SRB comprising 4 apartments is presented as the testbed, in which one PV, one battery and individual EWHs are considered to minimize the building's operation costs and determine the set points for the appropriate devices. The work presented here was performed within the EU Horizon 2020 project SENSIBLE (Storage Enabled Sustainable Energy for Buildings and Communities), as a part of the use case "Flexibility and demand side management in market participation". This case assumes a retailer, or other Energy Service company, aggregates a number of customers, and participates in a market in order to optimize its electricity costs and add value to the flexibilities that customers can offer.

To make a more realistic analysis, we forecasted the households' load behavior using data from the residential energy management equipment in SENSIBLE's Evora demonstrator [14].

The main contributions of this paper are the following: 1) interactions of electrical and thermal storage are analyzed in the context of SRB, and advantages of coordinated operation are shown; 2) To complement these interactions, cycling aging of the battery is included employing the RainFlow Counting Algorithm to model the complex cycling behavior; and finally, 3) The resulting non-linear and non-analytic problem is solved by the Particle Swarm Optimization, and as a result, two simple subproblems can be solved iteratively to find good quality solutions.

The present work is organized as follows: section II presents the mathematical formulation of the SRB. Next, section III sets out the solution algorithm used for the SRB energy management. The results obtained are given in section IV and finally, conclusions are drawn in section $\mathrm{V}$.

\section{Smart Residential Building Mathematical MODEL}

The proposed smart building is composed of a solar panel, a li-ion battery, a connection to the main grid, and a number of households. Each household contains a total electrical base load to be supplied and a thermal load that has to be met by an EWH, which also has the possibility of storing thermal energy.

In general, EWH input and electrical load during the $24 \mathrm{~h}$ period can be met by the main grid, the solar panel and the injected power from the batteries. The idea is to achieve a minimum operation cost by adjusting the setting of the devices in order to optimally manage resources. The scheme of the proposed SRB is shown in figure 1. As it can be seen, the battery and the PV serve all households in the building, whereas the thermal storage serves each apartment independently.

One feature of the proposed SRB is the possibility to independently control the Energy Storage System (ESS) and the Thermal Energy Storage (TES). This means that the secondary grid does not directly feed the thermostatic load In other words, this load is fed by the available stored energy

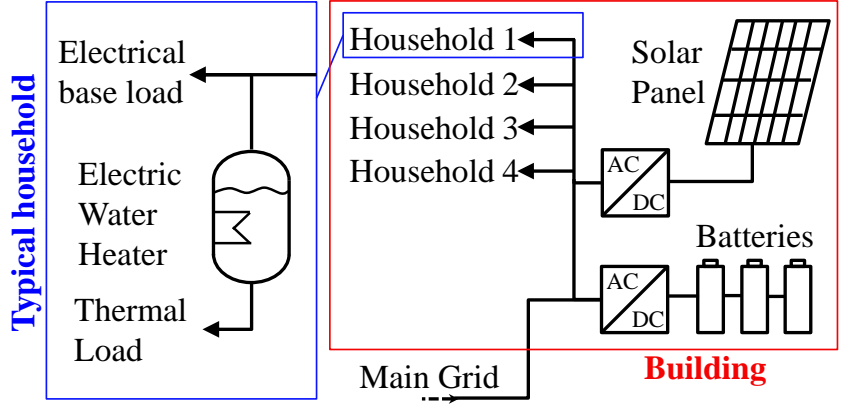

Fig. 1. Schematic diagram of the proposed SRB

in the TES, and the input for the EWH is seen as a load from the secondary network.

\section{A. Electrical load forecast}

The SENSIBLE project [15] explores integrating available technologies into the local power grid through 3 European demonstrators. The Evora demonstrator develops energy management applications and has therefore deployed smart-meters in a localized neighborhood of the city of Evora, Portugal. This smart meter roll-out features forecasting models developed to predict the electrical load demand of individual households.

To predict the electrical demand of one household for the next day, the model uses the demand during the previous week and the outside temperature predicted for the next day. By means of quantile smoothing spline fitting, it is possible to predict day-ahead demand $\hat{d}_{t}$ at instant $t$, as the sum of three functions:

$$
\hat{d}_{t}=f_{1}\left(d_{t-24}\right)+f_{2}\left(\bar{d}_{t}\right)+f_{3}\left(\hat{T}_{t}\right),
$$

where $d_{t-24}$ is the demand 24 hours before the instant to be predicted, $\bar{d}_{t}$ the median demand of the previous week and $\hat{T}_{t}$ the predicted temperature. After quantile regression, a set of forecast quantiles is obtained. Instead of a single-point value, $10 \%, 20 \%, \ldots, 90 \%$ values are obtained and respectively associated with a $10 \%, 20 \%, \ldots, 90 \%$ chance of measuring a lower actual demand at the instant predicted. This probabilistic forecasting of electrical demand is a point of interest in the literature [16], [17]. In the present work, the $50 \%$ value is taken for the electrical load input into the energy management optimization model.

\section{B. Mathematical model}

The model presented minimizes building operational costs by scheduling the battery power charge and discharge, and the power injected into the EWH. The proposed optimization model is shown and described in equations (2)-(13) and aims to minimize day-ahead operation cost for the smart building portfolio manager. The objective function considers the import energy cost and the cycling aging cost of the battery (second term in eq. 2).

Equation (3) expresses the power balance, where electrical base load and thermal load have to be supplied by the available resources and the purchased power in the wholesale market. 
Equations (4) and (5) describe the energy state for the battery and the EWH, respectively. In these constraints, the energy stored in time period $t+1$ is determined by the previous state of charge and the charge/discharge of the device in time period $t$ with the corresponding efficiency. It is important to mention that the term including $R$ and $C$ (thermal resistance and capacitance, respectively) in equation (5), represents the energy dissipation in the EWH as a measure of energy loss, as proposed in [11].

$$
\min \sum_{t=1}^{T} C_{i m}^{t} P_{i m}^{t}+C_{c y c}(D O D)
$$

s.t.

$$
\begin{gathered}
P_{i m}^{t}=\sum_{j=1}^{J} P_{L}^{t, j}+P_{C h}^{t}-P_{D C h}^{t}-P_{S}^{t}+\sum_{j=1}^{J} P_{H}^{t, j} \\
S O C^{t+1}=S O C^{t}+\eta^{c} P_{C h}^{t}-\frac{P_{D C h}^{t}}{\eta^{d}} \\
T S O C^{t+1, j}=T S O C^{t, j}+P_{H}^{t, j}-\frac{T S O C^{t, j}}{R^{j} C^{j}}-P_{L H}^{t, j} \\
S O C^{1}=S O C^{T} \\
S O C_{\min } \leq S O C^{t} \leq S O C_{\max } \\
T S O C_{\min }^{j} \leq T S O C^{t, j} \leq T S O C_{\max }^{j} \\
0 \leq P_{C h}^{t} \leq P_{C h}^{\max } \\
0 \leq P_{D C h}^{t} \leq P_{D C h}^{\max } \\
0 \leq P_{i m}^{t} \leq P_{i m}^{\max } \\
0 \leq P_{H}^{t, j} \leq P_{\operatorname{Hmax}}^{j} \\
t:\{1, \ldots, T\} \text { and } j:\{1, \ldots, J\}
\end{gathered}
$$

where

$t, j \quad$ Index time step and household respectively

$C_{i m}^{t} \quad$ Spot price at time $\mathrm{t}$

$\eta^{c} \quad$ Efficiency of battery charging

$\eta^{d} \quad$ Efficiency of battery discharging

$P_{S}^{t} \quad$ Power generated by the solar panels at time $t$

$P_{L}^{t} \quad$ Electrical base load at time $t$

$P_{L H}^{t, j} \quad$ Thermal load at time $t$ and EWH $j$

$S O C^{t}$ Battery state of charge at time $t$ with lower and upper bounds $S O C_{\min }$ and $S O C_{\max }$, respectively

$T_{S O C}{ }^{t, j} \quad$ State of charge at time $t$ and EWH $j$ with lower and upper bounds $T S O C_{\min }^{j}$ and $T S O C_{\text {max }}^{j}$, respectively

$P_{C h}^{t} \quad$ Power charged in battery at time $t$ with upper bound $P_{C h}^{\max }$

$P_{D C h}^{t}$ Power discharged in battery at time $t$ with upper bound $P_{D C h}^{\max }$

$P_{i m}^{t} \quad$ Power supplied from distribution grid at time $t$

$P_{H}^{t, j} \quad$ Power injected to the EWH $j$ at time $t$ with upper bound $P_{H \max }^{j}$

In order to maintain a constant operation feature of the battery, the accumulated energy at the end of the day must remain the same as it was at the beginning of the day (Eq 6). All variable limits are shown in constraints (7)-(12).

Function $C_{c y c}(D O D)$ is non analytic, given that the battery aging can only be calculated after ascertaining the SOC, and then determining the DOD at which each equivalent cycle occurs. Hence it is difficult to analytically model and express this phenomenon.
In order to overcome this difficulty, the problem formulated in (2)-(13) is solved with Particle Swarm Optimization (PSO), in which the decision variable is the battery's SOC. If SOCs are generated using this metaheuristic logic, the problem can be decomposed into two subproblems: one of them analyzes battery SOC proposals and calculates the corresponding cycling aging equivalent cost; the second subproblem calculates the day-ahead cost and the settings for the remaining building resources. Once the two subproblems are solved, the total cost can be obtained by simply adding both results (day-ahead and cycling cost). Details of these two subproblems will be explained in the next subsections.

1) Cycling Aging Cost Subproblem: Battery life in general can be expressed in terms of the actual lifespan of the device (calendar life) or the number of achievable charge and discharge cycles (cycle life) [4]. As already mentioned, the aging process is complex and depends on the cycling patterns, rates of charging/discharging, and consequent chemical reactions resulting in an accumulated history of voltages, currents and temperatures [3], and detailed analysis of this set of interactions is beyond the scope of this paper. The approach used in this work is based on the cycle life concept. In general, the maximum number of charge/discharge cycles for a battery at a certain value $d$ of DOD, is given by the following expression [18]:

$$
n_{d}=n_{100} d^{-k_{p}}
$$

where $k_{p}$ is a constant that depends on the life cycle - DOD curve given by the manufacturer, and can be extracted from the curve fitting. The quantity $n_{100}$ is the equivalent number of cycles before failure for $d=100 \%$.

Cycle counting for a specific DOD is identified from local extreme points based on the SOC curve, and equivalent half or full cycles are defined. This is carried out following the logic of the Rainflow Counting Algorithm (RCA), which is explained in detail in [19].

In the present work, a filtering process of the SOC is carried out before the RCA. This filtering considers two stages: first, adjacent local max/min points below a threshold $(<1 W h)$ are disregarded, i.e. the battery is in an idle state; second, intermediate points between local $\mathrm{max} / \mathrm{min}$ are eliminated, which leads to a stricter calculation of equivalent cycling.

Once the number of cycles and their DODs for the $24 \mathrm{~h}$ period have been calculated, an equivalent cycling cost is obtained according to the following expression:

$$
C_{c y c}=\sum_{j \in \Omega} L_{j} \frac{C_{i n i}}{n_{100}} d_{j}^{k_{p}}
$$

where $\Omega$ is the set of DODs for the analyzed period, and $C_{i n i}$ is the initial cost of the battery. The information of full or half cycles for each $d_{j}$ is given by $L_{j}$, taking values of 1 or 0.5 respectively. The obtained $C_{c y c}$ for a specific SOC is the equivalent cost due to the battery's aging process, and should be added to the total dispatch cost.

2) Day-ahead Thermal Subproblem: When the SOC for the battery is determined with the PSO, the problem in equations (2)-(13) has to be reformulated. This subproblem is called Thermal Subproblem, given that once an SOC is known, the 
remaining set points that need to be determined are those associated with the EWH.

First, $P_{C h}$ and $P_{D C h}$ can be easily determined by applying the following rule:

$P_{C h}^{t}= \begin{cases}\left(S O C^{t}-S O C^{t-1}\right) / \eta^{c}, & \text { if } S O C^{t}-S O C^{t-1}>0 \\ 0, & \text { otherwise }\end{cases}$

$P_{D C h}^{t}= \begin{cases}\left(S O C^{t-1}-S O C^{t}\right) \eta^{d}, & \text { if } S O C^{t-1}-S O C^{t} \geq 0 \\ 0, & \text { otherwise }\end{cases}$

It is worth noting that constraint (6) implies that both $P_{C h}$ and $P_{D C h}$ have to be zero for the first time frame $(t=1)$ in order to match the SOC for the last time frame of the previous day. Thus, equations (16) and (17) are valid for $t:\{2, \ldots, T\}$.

Once $P_{C h}$ and $P_{D C h}$ have been ascertained, a verification of these values is needed to determine whether they are higher than the nominal power. If so, the analyzed SOC is infeasible and a penalization of this proposal is needed. This penalization is calculated as follows:

$$
Y^{t}=1-H\left(P_{C h}^{\max }-P_{C h}^{t}\right)-H\left(P_{D C h}^{\max }-P_{D C h}^{t}\right)
$$

where $H(\cdot)$ denotes the Heaviside step function. From (18), whenever $P_{C h}^{t}$ or $P_{D C h}^{t}$ are outside the boundaries, $Y^{t}$ takes the value of 1; and if feasible operation is achieved, then $Y^{t}=$ 0 .

Once the value of $Y$ has been obtained, the model (2)-(13) can be rewritten in the following way as a linear programming problem:

s.t.

$$
\min v=\sum_{t=1}^{T} C_{i m}^{t} P_{i m}^{t}+\beta Y^{t}
$$

$$
\begin{gathered}
P_{i m}^{t}-\sum_{j=1}^{J} P_{H}^{t, j}=\alpha^{t} \\
T S O C^{t+1, j}=T S O C^{t, j}+P_{H}^{t, j}-\frac{T S O C^{t, j}}{R^{j} C^{j}}-P_{L H^{t, j}}^{t} \\
T S O C_{\text {min }}^{j} \leq T S O C^{t, j} \leq T S O C_{\text {max }}^{j} \\
0 \leq P_{i m}^{t} \leq P_{L}^{t} \\
0 \leq P_{H}^{t, j} \leq P_{H \max }^{j} \\
t:\{1, \ldots, T\} \text { and } j:\{1, \ldots, J\}
\end{gathered}
$$

where $\alpha^{t}=P_{L}^{t}+P_{C h}^{t}-P_{D C h}^{t}-P_{S}^{t}$ is now a known value. In addition, $\beta$ is a penalization factor when $P_{C h}$ or $P_{D C h}$ are outside the boundaries.

For each specific SOC, the corresponding fitness function is calculated by:

$$
f(S O C)=v+C_{c y c}
$$

where $v$ is obtained after solving the model (19)-(25) and $C_{c y c}$ from (15). In order to find an SOC that returns the minimum cost, the PSO metaheuristic is used, because it is capable of handling real variables and makes it east to integrate the two subproblems described in the previous paragraphs.

\section{Solution Methodology}

PSO algorithm is a metaheuristic optimization technique based on population behaviour, first proposed in 1995 [20]. The algorithm assumes the existence of $S$ particles. These particles move iteratively in an $\mathrm{N}$-dimensional search space, where the $i$-th particle can be represented by a vector $x_{i}=$ $\left(x_{i 1}, \ldots, x_{i N}\right)$. The velocity of each particle is denoted by $v_{i}=\left(V_{i 1}, \ldots, V_{i N}\right)$. In addition, information is kept for the best individual position for particle $i$ : $p_{\text {best }}=\left(p_{i 1}, \ldots, p_{i N}\right)$, and also for the best global solution $\left(g_{b e s t}\right)$ found. The particle velocity and its position for iteration $k+1$ are updated according to (27) and (28):

$$
\begin{gathered}
V_{i j}(k+1)=w V_{i j}(t)+c_{1} r_{1}\left(p_{\text {best }}-x_{i j}(t)\right)+c_{2} r_{2}\left(g_{\text {best }}-x_{i j}(t)\right) \\
x_{i j}(k+1)=x_{i j}(t)+V_{i j}(k+1)
\end{gathered}
$$

where $i$ is the particle index for $i=1, \ldots, S, j$ is an specific dimension for $j=1, \ldots, N, w$ is the inertia, $r_{1}$ and $r_{2}$ are two random numbers with uniform distribution in the range $(0,1)$, $c_{1}$ and $c_{2}$ are the cognitive and social parameters.

When a minimization problem is considered, the best individual position is updated according to equation (29) and $f(\cdot)$ is the objective function or the equivalent fitness function. Finally, the best particle in the swarm is updated with equation (30):

$$
\begin{gathered}
p_{\text {best }_{i}}(k+1)= \begin{cases}p_{\text {best }_{i}}(k), & \text { if } f\left(p_{\text {best }_{i}}(k)\right) \leq f\left(x_{i}(k)\right) \\
x_{i}(k), & \text { if } f\left(p_{\text {best }_{i}}(k)\right)>f\left(x_{i}(k)\right)\end{cases} \\
g_{\text {best }}(k+1)=\arg \min \\
p \in \text { best }_{i}
\end{gathered}
$$

The algorithm ends when at least one of the following criteria is met: 1) a maximum number of iterations is achieved, or 2) a maximum number of iterations without improving the fitness function is achieved.

To adapt the optimization problem described in II to be solved by the PSO, the codification of the particles should be determined. In this case, each particle $i$ refers to a SOC for the battery, which is composed of 24 elements $(N)$, associated with the 24 time steps for the day-ahead dispatch. Each particle should be assigned with a fitness function according to the equation (26). This means that for each particle in the swarm, the cycling and thermal subproblems described in subsections II-B1 and II-B2 need to be solved.

The initialization of the swarm is performed by randomly assigning SOC values to each specific time frame. The stop criterion used in this work is related to consecutive cycles without improving the fitness function.

The complete outline of the proposed algorithm is shown in 2 .

\section{RESULTS}

The proposed algorithm is coded in Python environment. The electric base load is generated using the logic explained in section II-A, for a selected set of 4 households in the Evora demonstrator on a typical day in November 2015. The 


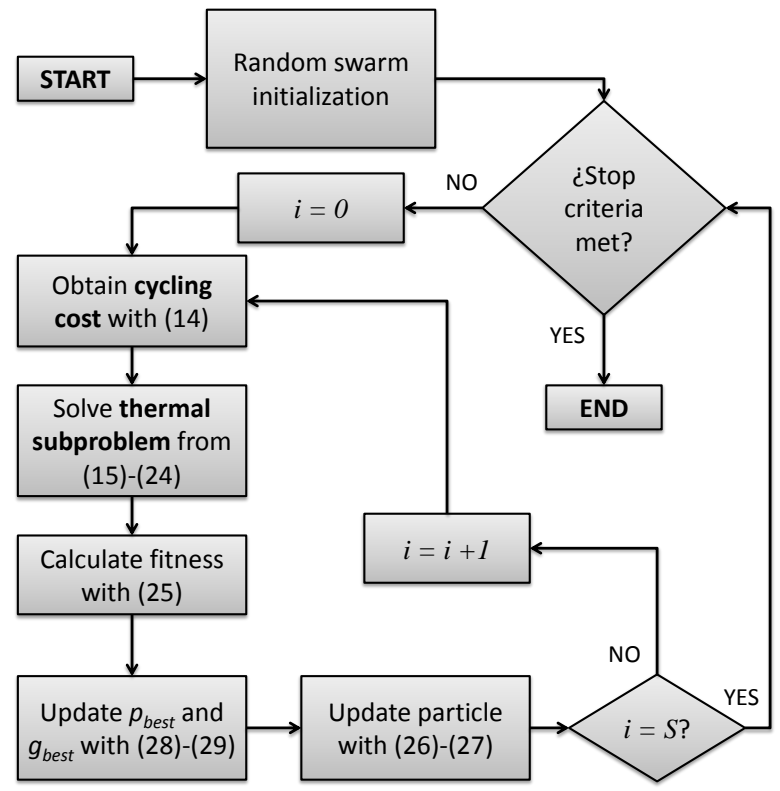

Fig. 2. Flowchart of the used PSO algorithm

4 households form the building to be analyzed. A normalized thermal load pattern is taken from [21], and its maximum level is adjusted to $25 \%$ of that of the electrical load, in order to reflect a more realistic behavior.

Electricity prices are those of a typical day in November 2015 for the French market and taken from the EPEXEuropean Power Exchange database [22].

The battery's maximum and minimum energy capacities are $80 \%$ and $20 \%$, respectively, based on reference [23]. Charging and discharging efficiency is assumed to be 95\%, and nominal power and capacity are $5 \mathrm{~kW}$ and $10 \mathrm{kWh}$, respectively; the size of the PV is $25 \mathrm{kWp}$. The cycling behavior is based on the li-ion battery information available in the market, and the curve fitting values to obtain the relation of cycle life versus DOD are taken from its technical sheet [24]. The coefficients obtained are $n_{100}=5135.7$ and $k_{p}=1.759$.

The battery cost is EUR $500 € / \mathrm{kWh}$, according to the latest IRENA information on residential storage systems for European countries [25].

The rated power/energy for the EWH, according to commercially available devices, is $6 \mathrm{~kW} / 15.3 \mathrm{kWh}$ respectively [26], and thermal resistance/capacitance are $568\left({ }^{\circ} \mathrm{C} / \mathrm{kW}\right) / 0.3483$ $\left(\mathrm{kWh} /{ }^{\circ} \mathrm{C}\right)$ according to [11].

\section{A. Coordinated versus uncoordinated storage without cycling aging}

A first test is carried out to determine the impacts of having only the flexibiliy given by the battery (uncoordinated scheme), versus the possibility of coordinated control for both battery and thermal storage. This test does not take into account cycling aging.

When no thermal storage is integrated into the building management system, the total operation cost is $15.11 €$. If coordinated control of both flexibilities is allowed, a lower cost is achieved: $13.54 €$. In addition, the SOC of the battery changes depending on the scheme. Figure 3 shows deeper cycling when only battery storage is considered, which will lead to a higher DOD and consequently a higher equivalent cycling aging cost. If equation (15) is used offline (after the scheduling of the resources) to determine this cost, associated values of 1.21 and $0.79 €$ are found for uncoordinated and coordinated approaches, respectively. This shows that integrating thermal storage not only reduces operation costs, but also indirectly extends the battery life, at least for the proposed testbed. The disaggregated TSOC for each EWH is shown in figure 3.

When the cycling cost for the coordinated approach $(-$ in fig. 3) is added offline to the day-ahead cost, a total of 14.33 $€$ is obtained. This would be the real cost of managing the SRB resources when cycling effects are not taken into account in the optimization process. The next section will explore the impact of integrated cycling on costs and equipment settings.

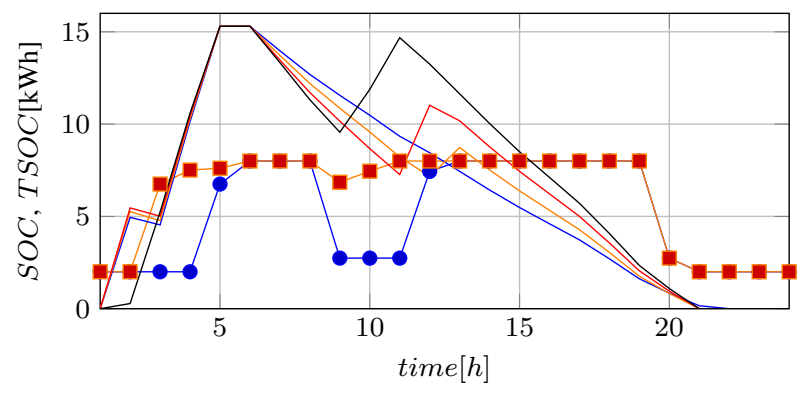

Fig. 3. Battery SOC for uncoordinated (- - ) and coordinated (management. TSOC for EWH in household 1 ( -$), 2$ ( -$), 3(-), 4$ $(-)$

\section{B. Management of coordinated resources considering cycling aging}

To determine how the cycling aging cost impacts on the management of resources, the methodology described in figure 2 is used. After several performance tests, the selected parameters for the PSO are $S=100, w=0.9 c_{1}=2$ and $c_{2}=2$.

When the proposed algorithm is implemented, the scheduling leads to a cost of $13.94 €$, with the SOC shown in figure 4 $(--)$. As it can be seen, the pattern changes in such a way that the battery is subject to less stress. In this case, the battery is cycled with maximum depths of $26.5 \%$, and the associated cost is already taken into account during the optimization process. It is also important to mention that initial $(t=1)$ and final $(t=24)$ SOC increase to $5.95 \mathrm{~kW}$, also helping to reduce the cycle depths.

This dispatch scheme, which represents a $2.72 \%$ cost reduction, is also important to overcome fluctuations in loads/renewable energy, given the presence of a margin of flexibility, which does not exist when storage devices are operating at their maximum or minimum values.

According to the EWH setting obtained, it can be seen from figures 3 and 4 that the stored energy changes in the first hours for heaters 1 and 4, and also for heaters 2, 3 and 4 around noon. Figure 5, shows that the proposed approach reduces the dependency of the main grid, by decreasing the power exchanged during the hours 9 to 13 . 


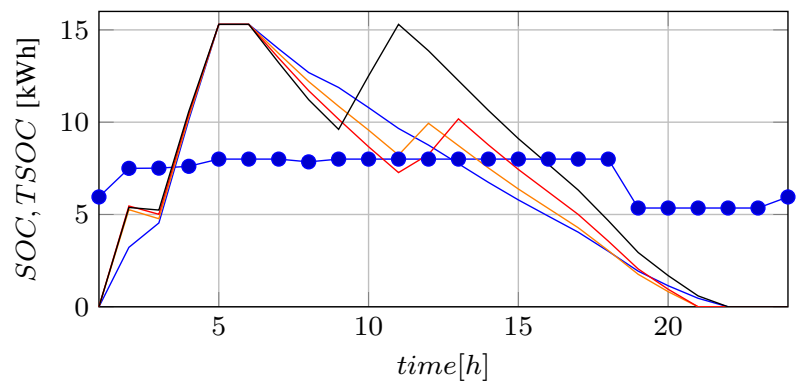

Fig. 4. Battery (- - ) SOC, and TSOC for EWH 1 ( -$), 2(-), 3$ $(\longrightarrow)$ and $4(-)$

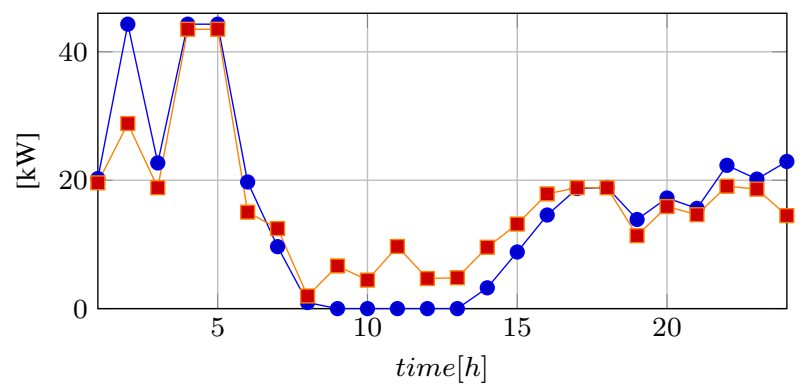

Fig. 5. Power fed by the main grid for the coordinated scheme with aging $(-)$ and without aging (- - )

\section{CONCLUSIONS}

A methodology for management of resources in SRB is proposed, where the coordination of thermal and electrical storage shows that reduced operation costs can be achieved. In addition, when considering the cycling aging cost there is a change in the device settings to avoid deeper and frequent cycling, while maintaining operation at a minimum cost.

The proposed scheme, which can also be used to analyze other sources of flexibilities and building configurations, shows that taking cycling into account also avoids operating batteries close to the max/min values, which can lead to employing flexibility to match variations in the load or available resources in real time operation.

The results presented could be further explored by diversifying the type of load that conforms the building, and also by creating an SRB network and analyzing different network topologies.

\section{REFERENCES}

[1] B. Zhou, W. Li, K. W. Chan, Y. Cao, Y. Kuang, X. Liu, and $\mathrm{X}$. Wang, "Smart home energy management systems: Concept, configurations, and scheduling strategies," Renewable and Sustainable Energy Reviews, vol. 61, pp. 30 - 40, 2016. [Online]. Available: http://www.sciencedirect.com/science/article/pii/S1364032116002823

[2] K. O. Aduda, T. Labeodan, W. Zeiler, G. Boxem, and Y. Zhao, "Demand side flexibility : Potentials and building performance implications," Sustainable Cities and Society, vol. 22, pp. 146-163, 2016. [Online]. Available: http://dx.doi.org/10.1016/j.scs.2016.02.011

[3] D. Dutt, "Life Cycle Analysis and Recycling Techniques of Batteries used in Renewable Energy Applications," 2013.

[4] D. Linden and T. B. Reddy, Handbook of batteries. New York, NY: McGraw-Hill, 2002.

[5] M. Zheng, C. J. Meinrenken, and K. S. Lackner, "Smart households : Dispatch strategies and economic analysis of distributed energy storage for residential peak shaving," Applied Energy, vol. 147, pp. 246-257, 2015 .
[6] R. Davies, M. Sumner, and E. Christopher, "Energy storage control for a small community microgrid," in 7th IET International Conference on Power Electronics, Machines and Drives (PEMD 2014), April 2014, pp. $1-6$.

[7] F. Geth, J. Tant, T. D. Rybel, P. Tant, J. Driesen, and D. Six, "Technoeconomical and life expectancy modeling of battery energy storage systems," in 21 CIRED International Conference on Electricity Distribution, June 2011, pp. 1-4.

[8] K. Darcovich, B. Kenney, D. D. Macneil, and M. M. Armstrong, "Control strategies and cycling demands for Li-ion storage batteries in residential micro-cogeneration systems," Applied Energy, vol. 141, pp. 32-41, 2015.

[9] G. Comodi, A. Giantomassi, M. Severini, S. Squartini, F. Ferracuti, A. Fonti, D. Nardi, M. Morodo, and F. Polonara, "Multi-apartment residential microgrid with electrical and thermal storage devices : Experimental analysis and simulation of energy management strategies," Applied Energy, vol. 137, pp. 854-866, 2015.

[10] X. Li, T. Borsche, and G. Andersson, "PV integration in Low-Voltage feeders with Demand Response," 2015 IEEE Eindhoven PowerTech, PowerTech 2015, 2015.

[11] N. Good, E. Karangelos, A. Navarro-Espinosa, and P. Mancarella, "Optimization under Uncertainty of Thermal Storage-Based Flexible Demand Response with Quantification of Residential Users' Discomfort," IEEE Transactions on Smart Grid, vol. 6, no. 5, pp. 2333-2342, 2015.

[12] Z. Xu, X. Guan, Q.-s. Jia, S. Member, J. Wu, D. Wang, and S. Chen, "Performance Analysis and Comparison on Energy Storage Devices for Smart Building," vol. 3, no. 4, pp. 2136-2147, 2012.

[13] A. Ouammi, "Optimal Power Scheduling for a Cooperative Network of Smart Residential Buildings," vol. 7, no. 3, pp. 1317-1326, 2016.

[14] G. Mendes, F. Guerra, A. Ferreira, L. Rocha, R. Bessa, C. Gouveia, and C. Murphy-OConnor, "Sensible project: Evora demonstrator enabling energy storage and energy management creating value for grid and customers," in CIRED 2016 workshop, June 2016.

[15] Project SENSIBLE. [Online]. Available: http://www.h2020-projectsensible.eu/sensible/index.aspx

[16] A. Gerossier, R. Girard, G. Kariniotakis, and A. Michiorri, "Probabilistic day-ahead forecasting of household electricity demand," in In revision CIRED 2017, June 2017.

[17] T. Hong and S. Fan, "Probabilistic electric load forecasting: A tutorial review," International Journal of Forecasting, vol. 32, no. 3, pp. 914938, 2016.

[18] G. He, Q. Chen, C. Kang, S. Member, P. Pinson, S. Member, Q. Xia, and S. Member, "Optimal Bidding Strategy of Battery Storage in Power Markets Considering Performance-Based Regulation and Battery Cycle Life," pp. 1-9, 2015.

[19] M. Musallam and C. M. Johnson, "An Ef fi cient Implementation of the Rain fl ow Counting Algorithm for Life Consumption Estimation," vol. 61, no. 4, pp. 978-986, 2012.

[20] R. Eberhart and J. Kennedy, "A new optimizer using particle swarm theory," in Micro Machine and Human Science, 1995. MHS '95. Proceedings of the Sixth International Symposium on, Oct 1995, pp. 39-43.

[21] C. Marnay, G. Venkataramanan, M. Stadler, A. Siddiqui, R. Firestone, and B. Chandran, "Optimal Technology Selection and Operation of Commercial- Building Microgrids - LBNL No. 62315," IEEE Trans. Power Syst., vol. 23, no. 3, pp. 1-10, 2007.

[22] "Epex spot auction, day ahead price for french market, nov. 2nd 2015," https://www.epexspot.com/en/marketdata/dayaheadauction/chart/auction-chart/2015-11-02/FR/1d/7d, accessed: 2016-10-13.

[23] D. Xu, P. Li, and B. Zhao, "Optimal scheduling of microgrid with consideration of demand response in smart grid," in Networking, Sensing and Control (ICNSC), 2015 IEEE 12th International Conference on, April 2015, pp. 426-431.

[24] "Saft batteries lithium ion battery life, may 2014," saftbatteries.com/force_download/li_ion_battery_life_TechnicalSheet_en_0514 Protected.pdf.

[25] Battery Storage for Renewables: Market Status and Technology Outlook, IRENA International Renewable Energy Agency, 2015. [Online]. Available: http://www.irena.org/documentdownloads/publications/irena_battery _storage_report_2015.pdf

[26] Electric space and water heating management system, technical specifcations, DIMPLEX Unvented Hot Water Cylinders. [Online]. Available: dimplex.co.uk/assets/kb/brochure/0/Quantum_Cylinder_Brochure.pdf 